\title{
Posterior fusion of lumbosacral vertebrae-blepharoptosis syndrome
}

INSERM

\section{Source}

INSERM. (1999). Orphanet: an online rare disease and orphan drug data base. Posterior fusion of lumbosacral vertebrae-blepharoptosis syndrome. ORPHA:2064

Posterior fusion of lumbosacral vertebrae-blepharoptosis syndrome is characterized by congenital ptosis and posterior fusion of the lumbosacral vertebrae. It has been described in a mother and her two daughters. 